5 Kingdon D, Vincent S, Selvaraj S, Kinoshita Y, Turkington D. Destigmatising schizophrenia: changing terminology reduces negative attitudes. Psychiatr Bull 2008; 32: 419-22.

David Kingdon, University of Southampton, Royal South Hants Hospital, Southampton SO14 OYG. Email: dgk@soton.ac.uk; Yoshihiro Kinoshita, University of Southampton, Paul Hammersley, University of Lancaster; Lars Hansen, Shanaya Rathod, Hampshire Partnership Trust; Farooq Naeem, University of Southampton; Douglas Turkington, University of Newcastle, UK

doi: 10.1192/bjp.194.6.569a

Author's reply: In an attempt to come up with new terminology, I sought to combine scientific evidence for valid contrasts with scientific evidence for a mechanism (aberrant assignment of salience) that refers to a psychological process that the general public can recognise and relate to, although a considerable amount of explanation may be necessary (see my reply to Bill George $\left.^{1}\right)$. Kingdon et al propose a different approach: they select possible risk factors and mechanisms associated with schizophrenia and investigate whether aetiological diagnostic constructs based on these are acceptable to patients. To the degree that their method included an analysis of acceptability to patients, ${ }^{2}$ their proposal is certainly superior to mine. A weakness of the method may be that there is little evidence that, for example, trauma and drug use underlie discrete effects that can be separated diagnostically. If anything, research suggests that there may be interacting causes that have an impact on the same final common pathway., Although it could certainly be argued that as long as there are established risk factors (although doubts exist ${ }^{5,6}$ ) and the terminology is acceptable to patients, this should not prevent their use as aetiological diagnostic constructs: a major problem would remain - acceptability to mental health professionals. How likely is it that these constructs would be accepted by the DSM and ICD committees currently revising diagnostic criteria? In my view, if we really want to abandon the stigmatising term of 'mind-split disease', it is important to come up with an alternative that is not only acceptable to patients, but also to mental health professionals. The reason for this is that DSM and ICD terminology is by far the most influential in how the general public attempts to understand 'madness'. Therefore, unless DSM and ICD terminology is changed, the part of the stigma that is induced by confusing and mystifying terminology will not change. Also, the continued use of the term 'psychosis' proposed by Kingdon et al may perpetuate the mystification of the experiences of patients, as the public cannot understand this term to make a connection to their own psychological experiences.

The most important issue, however, is how many patients, professionals and other stakeholders want the name to change. It certainly seems that many are of the opinion that a confusing and mystifying 19th-century term should not be used to diagnose patients in the 21 st century. Maybe the time has come for the DSM and ICD committees to make a decision on this topic and, in the case a name change is favoured, to develop a process through which a change that is acceptable to as many stakeholders as possible is achieved. The methodology of consulting patients developed by Kingdon et al should figure prominently in this endeavour.

1 van Os J. Salience dyregulation syndrome: a patient's view (author's reply). Br J Psychiatry 2009; 194: 467.

2 Kingdon D, Gibson A, Kinoshita Y, Turkington D, Rathod S, Morrison A. Acceptable terminology and subgroups in schizophrenia: an exploratory study. Soc Psychiatry Psychiatr Epidemiol 2008; 43: 239-43.

3 Cougnard A, Marcelis M, Myin-Germeys I, De Graaf R, Vollebergh W, Krabbendam $L$, et al. Does normal developmental expression of psychosis combine with environmental risk to cause persistence of psychosis? A psychosis proneness-persistence model. Psychol Med 2007; 37: 513-27.
4 Houston JE, Murphy J, Adamson G, Stringer M, Shevlin M. Childhood sexual abuse, early cannabis use, and psychosis: testing an interaction model based on the National Comorbidity Survey. Schizophr Bull 2008; 34: 580-5.

5 Macleod J, Davey Smith G, Hickman M, Egger M. Cannabis and psychosis. Lancet 2007; 370: 1539

6 Morgan $\mathrm{C}$, Fisher $\mathrm{H}$. Environment and schizophrenia: environmental factors in schizophrenia: childhood trauma - a critical review. Schizophr Bull 2007; 33: $3-10$.

Jim van Os, Department of Psychiatry and Neuropsychology, Maastricht Univeristy Medical Centre, PO Box 616 (DRT 10), Maastricht, The Netherlands. Email: j.vanos@sp.unimaas.n

doi: 10.1192/bjp.194.6.570

\section{Abortion and mental health disorders}

The paper by Fergusson et al, ${ }^{1}$ accompanied by comments, is a valuable addition to knowledge on this topic, but I should like to mention two issues which limit the usefulness of what is presented.

First, neither Fergusson nor the commentators give sufficient emphasis to the fact that that the communities of the Christchurch area of New Zealand are relatively prosperous and well organised compared with those in many parts of the rest of the world. The study findings cannot be extrapolated to communities where poverty, various degrees of malnutrition, and scarce medical and social services are common. In such communities, the modest level of what Fergusson et al call 'mental disorders' is likely to be present in many persons whether pregnant or not, and the significance of an unwanted pregnancy is also likely to be quite different from what it might be in more prosperous settings. How these issues interact can only be examined by direct studies in different communities.

Second, one of the commentators (Professor Patricia Casey) presents herself as 'not a member of any campaigning organisation', and also lists a number of her other activities to do with abortion and related issues. But there is no mention (probably due to the never-ending search for brevity that plagues us all) of the fact that she is a sincere member of the Roman Catholic Church, and that she always takes what can be called the 'pro-life' side in debates about abortion and related issues. Professor Casey is, of course, completely entitled to her opinions, and I have no doubt that she is proud of her activities in this difficult field and would never wish to hide them. But in these debates we all start from a position determined in part by personal background, and readers will not fully understand comments unless such things are known.

1 Fergusson DM, Horwood $\mathrm{L}$, Boden JM. Abortion and mental health disorders: evidence from a 30-year longitudinal study. Br J Psychiatry 2008; 193: 444-51.

John E.Cooper, Emeritus Professor of Psychiatry, University of Nottingham, UK. Email: johncooper@ntlworld.com

doi: 10.1192/bjp.194.6.570a

Author's reply: Professor Cooper suggests that the findings we report may not describe the linkages between abortion and mental health in communities that are more impoverished than the relatively advantaged New Zealand community that we studied. We agree that it would be rash to generalise our findings to these contexts. We are of the view that it is important that research into this topic is conducted in communities where material and economic conditions may make unwanted pregnancy a far more serious and stressful life event than is the case for relatively 